each year. If immigration continues at the present rate 800-1,000 new cases of tuberculosis in immigrants from Asia can be expected annually.

The experience in Bradford endorses the recommendations of the Tuberculosis and Diseases of the Chest Group Committee. Furthermore, the committee advocates that all immigrants, whether from the Commonwealth or not, should have an $x$-ray examination of the chest at the point of arrival in the United Kingdom. The success of the anti-tuberculosis programmes towards the eradication of tuberculosis is not an achievement which should be regarded lightly and is one that we should endeavour to maintain.

\section{Summary}

Tuberculosis in Pakistanis is 30 times more common than in the British population.

Of the Pakistanis with tuberculosis, $33 \%$ are diagnosed within 12 months of immigration and between 40 and
$50 \%$ have abnormal $x$-ray pictor at the time of immigration.

Of the Pakistanis with tubercukosis, 50\% develop the disease in this country.

The recommendation of the Tuberalosis and Diseases of the Chest Group of the British Medical Association is strongly endorsed-namely, that all immigrants should have an $x$-ray examination of the chest at the port of entry into the United Kingdom.

I thank Dr. D. M. Prinsley, who was deputy superintendent of Middleton Hospital at the time of the investigation, and who reviewed all the cases and made many helpful suggestions, and Dr. John Douglas, M.O.H. Bradford, who gave every available assistance.

\section{REFERENCES}

Brit. med. J., Suppl., 1961, 2, 254.

Corbett, J. T. (1961). J. Coll. gen. Practit., 4, 332.

Roe, J. T. Nicol. (1959). Tubercle (Lond.), 40, 387.

Shah, J. R., Warawdekar, M. S., Mehta, R. H., and Deshmukh, P. A. (1960). Indian J. med. Sci., 14, 948 .

Springett, V. H. (1958). Brit. J. prev. soc. Med., 12, 135.

\title{
TUBERCULOSIS AMONG INDIAN IMMIGRANTS TO A MIDLAND INDUSTRIAL AREA
}

\section{J. ASPIN, M.A., M.D., D.M.R.D.}

At the end of 1960 it was estimated that there were in the Wolverhampton neighbourhood some 3,000 adult Indian immigrants and a very much smaller number of Pakistanis, altogether amounting to about $2 \%$ of the local adult population. Before 1954 there were few Asiatic immigrants. In 1954 and in each subsequent year up to 1959 larger, though unascertained, numbers arrived each year, some to stay, others to move to other areas. Restrictions imposed by the Government of India temporarily slowed down the rate of emigration, but since 1960 Indians have again been arriving in rapidly increasing numbers. These later immigrants include a higher proportion of wives and families.

\section{Incidence}

Between 1950 and 1954 there was only one known Indian case of pulmonary tuberculosis in the area. Since January, 1954, 62 adult Indians and five adult Pakistanis have been found to be tuberculous, 60 with pulmonary and seven with non-pulmonary disease. It is interesting to note that of the 62 Indians, $41(66 \%)$ came from the Jullundur districts of East Punjab and $10(16 \%)$ from Surat districts near Bombay, a distribution which is as unlikely to have arisen by chance as the reported predominance of Gujeratis in another Midland area only a few miles away, and the extremely high proportion of Pakistanis among the Asiatic immigrants in Bradford (D. K. Stevenson, 1959, personal communication).

Although it is realized that this type of selective immigration to localized areas may lead to local differences in the prevalence of tuberculosis among Asiatics, for the sake of brevity in all that follows Indians and/or Pakistanis are referred to as Indians.

Table I shows the number of pulmonary tuberculosis cases diagnosed year by year. There are two striking points. Firstly, the annual local recognition of new cases among Indians is rising progressively. Secondly, among Indians arriving in 1954 and 1955 there has been a steady subsequent recognition of disease year by year up to 1961 .

TABLE I.-Year of Arrival and Year of Diagnosis Among 60 Indian Cases of Pulmonary Tuberculosis in the Wolverhampton Neighbourhood

\begin{tabular}{|c|c|c|c|c|c|c|c|c|}
\hline \multirow{2}{*}{ Year of Arrival } & \multicolumn{8}{|c|}{ Year of Diagnosis } \\
\hline & 1954 & 1955 & 1956 & 1957 & 1958 & 1959 & 1960 & 1961 \\
\hline Pre-1954 & 2 & 0 & 0 & 2 & 0 & 2 & $\begin{array}{l}0 \\
2\end{array}$ & $\begin{array}{l}0 \\
2\end{array}$ \\
\hline $\begin{array}{l}1954 \\
1955\end{array}$ & $\underline{0}$ & $\frac{1}{2}$ & 0 & 1 & $\frac{2}{3}$ & 2 & $\frac{2}{2}$ & $\frac{2}{3}$ \\
\hline & 二 & - & 0 & 0 & 1 & $\overline{0}$ & 2 & 1 \\
\hline & - & - & - & 0 & 1 & 0 & 3 & 2 \\
\hline 1958 & - & - & - & - & 0 & 2 & 1 & 2 \\
\hline & - & - & - & - & - & 0 & 1 & 2 \\
\hline & 一 & - & - & - & - & - & 2 & 4 \\
\hline Not known & 二 & 二 & 二 & 二 & 二 & $\overline{1}$ & 二 & $\underline{4}$ \\
\hline All years & 2 & 3 & 1 & 4 & 7 & 10 & 13 & 20 \\
\hline
\end{tabular}

Table II shows the rising proportion of Indians among locally diagnosed adult cases of pulmonary tuberculosis. Through lack of knowledge of the yearly number of Indians present in the area it is not possible to make wholly satisfactory comparisons. Assuming that during

TABLE II.-New Adult Cases of Pulmonary Tuberculosis in the Wolverhampton Neighbourhood, Showing the Proportion of Indians

\begin{tabular}{|c|c|c|c|c|c|c|c|c|}
\hline Year of Diagnosis & 1954 & 1955 & 1956 & 1957 & 1958 & 1959 & 1960 & 1961 \\
\hline & 238 & 222 & 241 & 216 & 194 & 162 & 159 & 181 \\
\hline $\begin{array}{l}\text { cases } \\
\text { Percent- }\end{array}$ & 2 & 3 & 1 & 4 & 7 & 10 & 13 & 20 \\
\hline $\begin{array}{l}\text { age of } \\
\text { totals }\end{array}$ & 0.8 & $1 \cdot 4$ & 0.4 & 1.9 & 3.6 & $6 \cdot 2$ & 8.2 & $11 \cdot 0$ \\
\hline
\end{tabular}

1960 there were 3,000 adult Indians and 150,000 other adults living in the area, and disregarding age differences, it appears that in 1960 over four times as many new cases of pulmonary tuberculosis were recognized among Indian immigrants as might have been expected among a similar number of local inhabitants. If it had been 
possible to work out age-specific attack rates the experience of the Indians might well have been shown to be even more unfavourable.

It is to be feared that even without allowing for the present increased rate of entry, and unless Indians move out of the area in large numbers, the local annual development of tuberculosis among them will increase progressively throughout this decade at least.

\section{Types of Tuberculous Disease Found Among Indian Immigrants}

There were seven adult cases of non-pulmonary tuberculosis with normal chest radiographs (three had abdominal disease, two had cervical adenitis, one had intercostal disease, and there was one case of epididymitis).

Inspection of the abnormal chest radiographs and clinical records of the 60 new pulmonary cases led to the conclusion that adult-type post-primary tuberculosis was present in 46 .

The remaining 14 cases with other pulmonary lesions included seven tuberculous pleural effusions, complicated in two by paratracheal and/or hilar adenitis ; five cases of hilar adenitis, complicated in one case by rib osteitis, in one by a scapular abscess, and in two by cervical adenitis; and two cases of miliary tuberculosis, one with a tuberculous lumbar vertebra and pubic bone. Having regard to date of arrival as well as clinical and radiological findings, it is not believed that the chest radiographs of any of these 14 cases would have been found abnormal at the time of entry.

The 46 patients with adult-type pulmonary tuberculosis included 13 who also had other tuberculous lesions: these were pleural effusions (5), hilar adenitis (2), cervical adenitis (2), bone tuberculosis (2), and intercostal abscess and peritonitis, one case each. The remaining 33 had adult-type pulmonary lesions only.

\section{Possibility of Pulmonary Disease Being Recognizable at Entry}

The chest radiographs of the 46 adult-type cases were then divided into those showing acute or chronic lesions. The radiographs of acute cases were defined as showing individually not very dense ill-defined "exudative" opacities and (if present) rounded often thin-walled cavities. Chronic mixed-type cases were to show, at least in part, some combination of more sharply defined or linear "productive" opacities, often with a suggestion of fibrosis or calcification. In Table III the 46 cases,

TABle III.-46 Indian Cases of Adult-type Pulmonary Tuberculosis Divided into Acute and Chronic Cases. Figures in Parentheses Relate to Cases Thought to Have Had Abnormal $X$-ray Appearances at Time of Entry

\begin{tabular}{|c|c|c|c|c|c|c|c|c|}
\hline \multirow{2}{*}{$\begin{array}{l}\text { Type of } \\
\text { Disease }\end{array}$} & \multicolumn{8}{|c|}{ No. of Years in England before Diagnosis } \\
\hline & 0 & 1 & 2 & 3 & 4 & $\begin{array}{l}5 \text { and } \\
\text { More }\end{array}$ & $\left|\begin{array}{c}\text { Not } \\
\text { Known }\end{array}\right|$ & Total \\
\hline $\begin{array}{l}\text { Acute } \\
\text { Chronic }\end{array}$ & $\begin{array}{l}6(3) \\
2(2)\end{array}$ & $4 \stackrel{2}{(4)}$ & $4 \stackrel{1}{(3)}$ & $\stackrel{8}{2}(1)$ & $\begin{array}{l}7 \\
0\end{array}$ & $\begin{array}{l}7 \\
2\end{array}$ & $\begin{array}{l}1 \\
0\end{array}$ & $\begin{array}{l}32 \\
14\end{array}$ \\
\hline
\end{tabular}

subdivided in this way, are set against years lived in England before diagnosis.

Acute disease was recognized in 32 cases, nine times among those diagnosed during their first three years in England and 23 times in later years. Although in the absence of earlier chest radiographs it is unwise to make a dogmatic statement, it is thought that all the latter 23 cases and six of the nine former cases would have had clear chest films if radiographed at entry; the remaining three are thought to have brought their disease with them. Two were blatant grossly diseased patients who had been in the country for only five months between them.

Chronic disease was recognized in 14 cases-10 of them during the first three years in England and four in later years. It is thought that in nine of these earlier arrivals there would have been an abnormal chest radiograph at entry. In one chronic case the patient, who had been four years in England, eventually stated that he had been treated for tuberculosis in India.

Before summarizing this section it should be said that Springett and others (1958), studying the diagnosis of tuberculosis among Asian immigrants to Birmingham during 1956 and 1957, concluded that the excess among the Asian-born was due to the immigration of persons already having tuberculous lesions. At that time, when large-scale immigration had begun only two years previously, this conclusion was justified. The later investigations of Stevenson (1959, personal communication) in Bradford among Pakistanis have shown that disease is also developing year by year among immigrants who might have been non-tuberculous at entry.

It is thought that, even on a generous assessment, no more than $13(19 \%)$ of the 67 adult Indian cases of tuberculosis occurring in the Wolverhampton neighbourhood during the past seven years would have been brought to notice by chest radiography at the time of entry. The rest can be assumed to have developed their disease in England, even though their housing and general living conditions, unfavourable according to local standards, are not likely to be inferior to those under which they were formerly living. None the less, if the 13 cases (and other as yet unknown potentially infectious cases) had been detected by chest radiography at the time of entry, some of the subsequent cases of tuberculosis developing among contacts in the crowded Indian-occupied houses might have been avoided.

\section{Comparison with Present-day Position in India}

Visitors to Indian military and civil hospitals during and after the last war can readily understand what is going on to-day among Indian immigrants. Although among Indian urban dwellers there is a high rate of tuberculin sensitivity, among villagers there may still be many tuberculin-negative young adults. When young people from stocks susceptible to tuberculosis move from isolated rural communities in an underdeveloped country into a crowded industrial environment, initially they will suffer an excessive development of tuberculous disease (Benjamin, 1957), with a high proportion of what in England to-day would be regarded as bizarre forms (see above ; also Silver and Steel, 1961).

Urban dwellers whose earlier equally susceptible neighbours have long since succumbed to infection before reproducing their genetic inheritance now tend to develop much more chronic disease.

In England the peak morbidity rates for tuberculosis among males are now shifting towards middle age and later. In India the peak is still among young adults. the very age-group from which most of the immigrants come. 
Treatment and Prevention

So far as treatment is concerned, Indian patients locally diagnosed as tuberculous have all gone into hospital when so advised, for triple-drug therapy. In spite of language difficulties, these Indians have co-operated well in their treatment. With one exception, all have been or should be made sputum-negative. If experience with earlier-diagnosed cases is any guide, they will continue to take antituberculous drugs at least as regularly as their English fellow-patients after returning to work. In this section the only possibly unfavourable factor is drug resistance, which has been recorded four times among the 60 cases. Primary resistance at the time of diagnosis was to streptomycin, P.A.S., and isoniazid, one case each. These three cases were rendered sputum-negative during standard triple-drug therapy. The fourth became resistant to streptomycin and P.A.S. during treatment (which began in 1955), but sputum-conversion was obtained after further treatment with isoniazid and viomycin.

The occurrence of three primarily resistant cases among the 28 Indians who were sputum-positive $(9.3 \%)$ compares unfavourably with the $3.1 \%$ primarily resistant cases recently described in England (Public Health Laboratory Service Report, 1961). Great care should be taken in the initial treatment of tuberculous Indians.

Original contacts have attended for examination and B.C.G. vaccination in large numbers, but language difficulties and the unfamiliar spelling and peculiar complexity of Indian names, together with frequent change of lodgings, make record-keeping and follow-up difficult. There is clearly a need for B.C.G. vaccination of newly arrived susceptible Indians (Corbett, 1961).

\section{The Diagnostic Problem}

In spite of the changed immigration policy there is still a two-stage diagnostic problem. Immigrants arriving in the area ought not to be allowed to join general practitioners' lists until satisfactory chest radiography reports have been received. Also, some system should be devised which will ensure that all these vulnerable Asiatic immigrants have their chests radiographed at least once a year. It is not enough to wait until the onset of symptoms sends them to their doctors and until their doctors then refer them to the chest service. By that time other susceptibles in the crowded households will have been at risk.

It is gratifying to find that some general practitioners are apparently referring Indian patients to chest $x$-ray units at every visit to their surgeries, a practice which could with profit be widely extended.

Locally, it has been decided that the most promising way to protect Indians in England, apart from urging all practitioners to refer new Indian patients to the $x$-ray units, is to make six-monthly visits to all known Indianoccupied premises, offering appointment cards for chest radiography to all present without going into too much detail about names or previous attendance. Latterly, the Assistant Commissioner to the Government of India has written a letter to all local Indian householders, and has himself visited many such houses urging attendance at $x$-ray units. Arrangements are also to be made for mass radiography units to visit the cinemas where special weekly programmes of Indian films attract large numbers of Asiatics.

\section{Summary and Conclusions}

Among the increasing numbers of Indian and Pakistani immigrants (mainly the former) who now make up about $2 \%$ of the adult population in the Wolverhampton neighbourhood there is an increasing recognition of tuberculous disease, probably amounting in 1960 to at least four times as much as among the local population.

Reasons are given for supposing that only $19 \%$ of the 67 cases recognized since 1954 would have been detected by chest radiography at the time of entry.

Among the 1954 and 1955 entrants there has been a steady development of tuberculosis year by year. It is feared that a similar future development among more recently arrived immigrants (if they stay) will lead to progressively increasing rates of local recognition of tuberculous disease among Indians, for the rest of this decade at least.

All Indians should be required in their own interest to have their chest radiographed after entry and before being accepted on to general practitioners' lists. Also, it is important that all Indian adults in this country should be sent for chest radiography at least annually. With proper treatment of newly diagnosed cases and by the practice of standard measures for contact review and B.C.G. vaccination of susceptibles, it can be hoped that, as among the English population, the present alarming development of tuberculous disease among Indians may be checked, if not reversed.

Dr. D. K. Stevenson has kindly allowed me to quote from his communication to the British Tuberculosis Association (Leeds, September, 1959) that there has been a steady annual development of tuberculosis among Pakistanis already resident for several years in Bradford.

\section{REFERENCES}

Benjamin, P. V. (1957). Procedings of XIV International Tuberculosis Conference, New Delhi, p. 17. Tuberculosis Association of India.

Corbett, J. T. (1961). J. Coll. gen. Practit., 4, 31, 332

Public Health Laboratory Service Report (1961). Tubercle (Lond.), 42, 308.

Silver, C. P. and Steel, S. J. (1961). Lancet, 1, 1254

Springett, V., H., Adams, J. C. S., D'Costa, T. B., and Hemming, M. (1958). Brit. J. prev. soc. Med., 12, 135.

\section{PREPARATION OF INDIVIDUAL INFUSION FLUIDS}

\section{A SIMPLIFIED SYSTEM}

BY

\author{
JAMES C. EATON, M.B., B.Sc., F.R.I.C. \\ University Department of Pathological Biochemistry, \\ Glasgow Royal Infirmary
}

The types of fluid given intravenously in the past have usually been planned on the view that anything given intravenously should be approximately isotonic with blood plasma. Consequently "normal" saline, 5\% glucose and M/6 sodium lactate, all approximately isotonic, have become traditional. That isotonicity is of little importance is experimentally obvious, since saline with $5 \%$ glucose is now one of the most widely used intravenous fluids although it has double the osmotic value of plasma. On the other hand, pure water may be and often is given intravenously without haemolysis. It is true that the glucose in saline with $5 \%$ glucose will be rapidly metabolized and its osmotic value will disappear, but this is equally true of $5 \%$ glucose without the saline. It is apparent, therefore, that hypotonicity is of little consequence and that hypertonicity at least up to double that of normal plasma need not normally be taken into account. 